ISSN: 2162-3104 Print/ ISSN: 2166-3750 Online Volume 7, Issue 2 (2017), pp. 163-187 (C) Journal of International Students http://jistudents.org/

\title{
Brazilian and Nigerian International Students' Conceptions of Learning in Higher Education
}

\author{
Carol Ashong \\ Nannette Commander \\ Georgia State University, USA
}

\begin{abstract}
The growth of international students compels examination of introspective aspects of learning experiences such as conceptions of learning. Additionally, learning conceptions profoundly impact learning outcomes (Tsai, 2009). To address the lack of research on learning conceptions of students from Africa and South America, this study examines Brazilian and Nigerian students' conceptions of learning while studying in the U.S. Reflective diaries and interviews reveal an awareness of learning as not limited to the classroom, along with clear themes regarding ideas about learning and actual learning experiences. Findings provide valuable information to institutions regarding academic support and assistance for international students.
\end{abstract}

Keywords: conceptions of learning, international students, Brazilian Students, Nigerian Students, higher education

One area of research that informs institutions about meeting the needs of international students is the literature on conceptions of learning. All students come to learning situations with different preconceived views of what "learning" means (Marshall, Summer, \& Woolnough, 1999). Conception1s of learning refer to students' fundamental understanding, or interpretation, of the learning phenomena (Marton, 1981) and have been defined as coherent systems of knowledge and beliefs about learning and phenomena related to learning (Marshall et al., 1999; Tsai, 2009; Vermunt \& Vermetten, 2004). In more depth, Cano and Cardelle-Elawar (2004) explained that learning conceptions are individual constructions that develop from knowledge and experience and dictate the different ways in 
which learning is understood. Vermunt and Vermetten (2004) argued that conceptions of learning include what an individual thinks about learning objectives, activities, strategies, tasks, and processes.

Students' conceptions of learning are important because they profoundly impact learning outcomes (Tsai, 2009) and influence students interaction with courses, classroom environment, teachers, and peers (Marshall et al., 1999). Further, learning conceptions include preconceived ideas about students' roles, the role of the instructor and other professionals in academia, and these ideas about roles and the relationships between all the different players in educational settings impact how students approach learning (Mclean, 2001). Tsai (2009) argued students' conceptions of learning guide primary beliefs about and interpretations of learning experiences as well as ultimately influence learning outcomes. Students' conceptions of learning have also been found to impact and predict academic achievement (Allan, 2003; Boulton-Lewis, Marton, Lewis, \& Wilss, 2000; Tsai \& Kuo, 2008). Cano and Cardelle-Elawar (2004) noted the more capable students are of deciding for themselves what learning means the more successful they are in their academic performance. It is therefore critical that educators are aware of and understand students' conceptions of learning.

\section{LITERATURE REVIEW}

When investigating international students' conceptions of learning, culture is an important construct to consider (Marshall et al., 1999; Tsai \& Kuo, 2008; Tsai, 2009). Hong and Salili (2000) argued that conceptions of learning are formed by cultural values. Purdie, Hattie, and Douglas (1996) stated that environment, where learning occurs, influences conceptions of learning, and culture is embedded in environment. The general assumption that learning is a well-defined standard experience across cultures has been challenged by research indicating students' conceptions of learning differ (Jones, 2008). For example, Purdie, Hattie and Douglas (1996) found Austrailian students have a narrow school based view of learning, while Japanese students have a broader, more community based view of learning. Along similar veins, Boulton-Lewis et al. (2004) reported differences in indigenous Australian and Australian university students' views in terms of learning as an increase in knowledge, memorizing and reproducing, applying, and understanding. Abhayawansa and Fonseca (2010) examining Sri Lankan students enrolled in an Australian university found that the students from Sri Lanka reported beliefs about learning being teacher centered, whereas their Australian classmates perceived learning as student centered. Research has reported that Asian students differ from their Western classmates because they consider learning to be more than the 
transference of knowledge and attending school (Jones, 2008). Jones (2008) reported that Asian students view knowledge as having to do with things that cannot be measured such as emotions, intuitive feelings, spirituality, morality, and social skills, and this view differs from traditional Western beliefs about learning being built upon things that can be scientifically proven.

Thus, students from various cultures differ in their conceptions of learning. However, research has predominantly been with "Western students," from Europe, North America, and Australia, who are compared with those from "non-Western" cultures, usually represented by Asia. The general trend is to rely on investigations in these regions as the basis for cross-cultural theorizing, and students from other geographical locations are not included in the literature (Abhayawansa \& Fonseca, 2010; Jones, 2008; Marshall et al., 1999; Purdie et al., 1996; Tsai \& Kuo, 2008; Tsai, 2009). In particular, South American international students' conceptions of learning are not typically investigated although this population is steadily increasing in the U.S, with most students arriving from Brazil (Castaneda, 2008; Downie, 2005).

According to the International Institute of Education, 23, 675 Brazilian students were enrolled in universities in the U.S. during the 20142015 academic year. Brazil is currently the sixth leading place of origin for students coming to the U.S. African international students' conceptions of learning are also not being addressed although the number coming to the U.S. is increasing with Nigeria sending the most students. According to the IIE's open door report (2015), Nigeria is the fifteenth leading place of origin for students coming to the U.S. During 2014-2015 academic year, 9, 494 students from Nigeria were studying in the U.S. Although previous research encourages concentrating on international students from Brazil and Nigeria due to their steadily increasing numbers (Castaneda, 2008; Downie, 2005), very few investigations focus solely on these two groups of students.

Previous research encourages concentrating on international students from Brazil and Nigeria due to their steadily increasing numbers (Castaneda, 2008; Downie, 2005). Yet very few investigations focus solely on these two groups of students. Some research that includes international students from Africa has addressed transition problems (Adelegan \& Parks, 1985), racial identity (Phinney \& Onwughalu, 1996), and cultural adjustment (Constantine, Anderson, Berkel, Caldwell, \& Utsey, 2005). One of the few studies with international students solely from Africa examined female scientists enrolled in Western universities. Results revealed that White professors questioned the students' ability to do the work, asked them to take remedial classes, and criticized their accents (Beoku-Betts, 2004). Additionally, participants experienced feelings of exclusion and a lack of support emanating directly from prejudicial attitudes. Similarly, few studies have focused on international students 
from South America. Wilton and Constantine (2003) found high levels of psychological distress among South American international students. More recently, Reynolds and Constantine (2007) examined South American students' sense of social and academic competence and reported that a lack of confidence in their social, academic, and career contexts might have a profound effect on their future career goals and aspirations. Castaneda (2008) examined the academic needs of South American students and found that second language problems, quality of academic advisement, availability of financial support, level of integration into their academic program, and cultural adjustment impact their academic experiences.

Some research has focused specifically on the conceptions of learning of students in Brazil and Nigeria. One reported Brazilians view learning as not constrained to a formal learning environment but an ongoing process in everyday life (Crabtree \& Sapp, 2004). This study also found students in Brazil believe learning takes place when there is a social, emotional, and physical closeness between teachers and learners. These findings are supported by Santilli, Miller, and Katt (2011) who found Brazilian students are comfortable spontaneously greeting their teachers on the street with an embrace and a kiss on the cheek and expect instructors to be actively interested in their personal as well as academic affairs. However, Fidalgo-Neto et al. (2009) found that in learning settings in Brazil teachers play a central role in knowledge transference, and students play a more passive role in their learning process. Watkins and Akande (1994) reported Nigerian students believe that they do not play an active role in learning, and it is the responsibility of the teacher to pass down knowledge to them. This study also reported students prefer a less competitive classroom environment. Sunal, Inuwa, Sunal, and Haas, (2001) similarly reported Nigerian students believe learning takes places through hands-on experience but teachers play a governing role in the learning process, with students expected to follow and cooperate with the teacher. This study also found students in Nigeria view learning as something that should be practical and applicable to everyday life instead of being theoretical. Another study reported students in Nigeria believe learning is a group activity and as a result often participate in cooperative learning (Iyamu \& Ukadike, 2007). While these studies provide valuable information on Brazilian and Nigerian students' conceptions of learning, it is important to note that data was collected in the students' countries of origin.

\section{RESEARCH METHOD}

This study was carried out in an urban university in the Southwestern United States. Students may be experiencing or may already have experienced conflict between what is presented and expected in the American university setting and experiences in their home cultures, so their 
conceptions may be fluid and shifting. At the time of the study no other research had investigated Brazilian and Nigerian students' conceptions of learning while studying in the U.S., and no other research has examined both groups within the same study. Thus, this study was exploratory in nature. Findings from this study provided information on Brazilian and Nigerian students' conceptions of learning and inform instructors of international students and international programs in general. The research questions were: 1) What are Brazilian and Nigerian students' conceptions of learning? 2) Are there differences and/or similarities between their conceptions of learning and learning experiences in the United States? 3) Are there differences and/or similarities between the two groups in their conceptions of learning?

This study was informed by grounded theory developed by Glaser and Strauss (1967) whereby researchers discover concepts and hypotheses through the method of constant comparative analysis. This methodology, best suited for exploring social phenomena and the behavior of groups allows a shift from existing theory to themes that emerge from current data and focuses on areas with little or no literature (Glaser \& Strauss, 1967).

\section{Researcher's Positionality}

First author's experiences of crossing cultural borders as an international student informed this research and contributed toward efforts to be transparent. I came to the United States as an international student for undergraduate and graduate studies 11 years ago and therefore closely related to the participants in this study. As a Ghanaian international student, I continuously examined my relationship to the participants and the study. Though my familiarity with the experiences of the participants presented somewhat of a challenge to my objectivity, I was also well aware that my identity as an international student did not necessarily mean that the participants and I had the exact same experiences. However, I had an "insider" status because of shared similar cultural and educational experiences, and I constantly reflected on this during the research process. My insider status also influenced the way participants engaged with me. In fact, participants often expressed they were comfortable talking to me because they felt I could relate to them and the experiences they shared with me. Our shared status as international students was advantageous and helped build a cordial and trusting relationship that allowed the interviews to run very smoothly. In some instances participants asked if I understood the experiences they shared or if I had similar experiences. I refrained as much as possible from sharing my experiences so as not to influence participants' responses. Some participants asked me questions about my experiences as an international student, expressing curiosity about my learning experiences. I made efforts to always keep their experiences the 
focus of the conversations and reflecting on this positionality allowed me to find the middle ground.

My reflections during the research process heavily relied on theoretical sensitivity and reflexivity. Theoretical sensitivity refers to the researcher's ability to use personal and professional experiences together with methodological knowledge to see data in new ways and think abstractly about data in the process of developing theory (Glaser \& Strauss, 1967; Strauss \& Corbin, 1998). However, since theoretical sensitivity may create a situation where the researcher explains data in a biased way, the process should be complemented by reflexivity. Reflexivity is defined by Horsburgh (2003) as "active acknowledgement by the researcher that his or her own actions and decisions will inevitably impact upon the meaning and context of the experience under investigation" (p. 308). Reflexivity allows researchers to deconstruct who they are and the ways in which their beliefs, experiences, and identity intersect with that of the participants (Macbeth, 2001). This reflection occurs both in individual thought and through dialog with others that acknowledges the researcher's own experience and perspectives (Johnson \& Waterfield, 2004). Instead of trying to hide behind a false sense of objectivity, the researcher makes his or her own sociocultural position explicit. For example, reflexivity requires researchers to question how the "researcher-participant interaction" and the researcher's perspective affect the analysis and the results (Hall \& Callery, 2001). Reflexivity is a process that occurs throughout every stage of research (Guillemin \& Gillam, 2004). Guided by theoretical sensitivity, my personal and academic experiences as an international student allowed me to view the data in new ways and think abstractly about the data. Also, I actively engaged in constant reflexivity throughout the stages of research design, data collection, and analysis.

In addition to theoretical sensitivity and reflexivity, I employed various techniques recommended by and Lietz, Langer, and Furman (2006) and Shenton (2004) to ensure the trustworthiness of qualitative research. Shenton (2004) suggests that it is important to use well-established research methods and triangulate by using different methods of data collection for rigor. This study was informed by grounded theory, a well-established methodology, and employed the use of interviews and reflective diaries as established methods of data collection. The use of two data sources in this study, in addition to theoretical memos, allowed for triangulation and contributes towards the credibility and trustworthiness of the research. It is important that qualitative researchers help ensure honesty from participants by giving them opportunities to refuse participation to make sure that data collection involves only those who are genuinely willing to take part and prepared to offer data freely (Shenton, 2004; Lietz et al., 2006). Accordingly subjects were informed that their involvement was strictly voluntary, and they could refuse and/or stop participation at any time. This 
study employed the use of iterative questioning which Shenton (2004) argues allows the researcher to return to matters previously raised by participants and extract related data through rephrased questions. A second round of interviews gave opportunities for issues raised in student diaries to be further explored and clarified.

\section{Participants}

Thirteen $(N=13)$ students participated in this study - (six from Brazil, seven from Nigeria, eight females, five males). Length of stay in the U.S. ranged from six months to four years, with an average of a year. Data was collected in the spring semester of 2014. After the researcher gained IRB approval from the university, participants were recruited through emails sent by the international education office to currently enrolled undergraduate students from Brazil and Nigeria. Those who responded were asked to contact the researcher directly and to forward the email to other students from Brazil and Nigeria who might be interested in taking part in the study. The researcher then sent information on the study and requirements for participation to all students. The researchers collected data through initial interviews, reflective diaries, and final interviews. Consent forms were provided at initial interviews, and all interviews were semistructured, audio-recorded, and at a location of the participants' choosing. Initial interviews lasted approximately an hour and a half and were guided by questions previously used in the literature (Marshall et al., 1999; Tsai, 2009 \& Tsai \& Kuo, 2008): What is your definition of learning? How do you learn best? How do you know when you have learned something? and what do you think makes up a good learning environment? Participants were asked to reflect upon experiences in ways that rarely occur in everyday life (Charmaz, 2006). The rationale behind initial interviews was to create rapport between the participants and researcher and prompt participants' thinking about learning experiences. After initial interviews participants were instructed to keep a diary for one week by selecting one learning experience connected to their education daily and reflect on it using these guiding questions from previous research (Marshall et al., 1999; Tsai, 2004 \& Tsai \& Kuo, 2008): What did you learn? (Describe the learning experience), what did you find satisfying or frustrating in your learning experience? When were you aware that you had learned something? How did you feel if you thought you were not learning as you should? and What about this learning experience was different from previous experiences? Participants were instructed to address other issues believed to be pertinent, provide examples connected to their reflections, state the date and time at the start of every reflection, and contact the researcher if they had questions. No restrictions were placed on the length or format of the diaries. None of the participants contacted the researcher 
during the week of diary entry for clarification on requirements and expectations. The use of reflective diaries within research and formal learning settings as a way to deepen learning and stimulate critical thinking has increased in recent years (Prinsloo, Slade, \& Galpin, 2011). Reflective diaries are useful mechanisms that can move students beyond simple observation towards deeper reflection, analysis, synthesis, and critique (McGuinness \& Simm, 2005; Travers, 2011). Once participants submitted their diaries, final interviews were scheduled.

The purpose of the final interviews was to clarify and explore issues addressed in the diaries and gain further information on the students' broader views about learning. Audio-recorded semi-structured final interviews lasted approximately an hour and were guided by the following questions: Do you use the same or different approaches to learning in the U.S. that you used at home? What have you found fulfilling or frustrating about approaches that are new to you versus ones that you used to at home? Do you find that the learning experiences you have in the U.S. are different from or similar to learning experiences you had at home? Do you find that the learning environments you experience in the U.S. are different from or similar to the learning environments you experienced at home? Do you feel you are learning more, less or differently than what you were accustomed to previously? and how would you say the process of adapting to a new learning environment has been like for you. Whereas initial interviews concentrated on asking students abstract questions about learning in order to explore how they would respond independently, final interview questions were more specific in order to guide students to think about how learning experiences in their home culture compared to those in the U.S. The time period between initial and final interviews was approximately two to three weeks.

\section{Data Analysis}

Interviews were transcribed verbatim and each diary read thoroughly to develop an empathetic understanding of individual views. Following the hierarchical coding process of grounded theory, open, lineby-line coding was conducted followed by axial coding that specifies relationships between categories (Hallberg, 2006). Open coding involved reading all interview transcripts and diaries line by line several times and creating tentative labels for chunks of data that summarized or represented distinct concepts and categories, which formed the basic units of analysis. Focus during this stage of analysis was on highlighting descriptive keywords and phrases pertaining to learning. Axial coding involved deconstructing each category that emerged during open coding into subcategories. Relations between emerging categories and between categories and their properties were identified and verified in the data to ensure that these conceptual relationships were grounded in the data. The 
text was re-read to confirm that categories accurately represented participant responses. The final stage of analysis was an integration of empirical data with theoretical memos. Through this process, the themes and categories that emerged from both sources were identified. In accordance with the constant comparative process, after initial categories were coded during open coding, incidents applicable to each category were compared. Each incident in the data was coded into as many categories as possible. Analysis of data then shifted from comparing participant's responses to one another to comparing individual responses to categories and their properties. NVivo 7, a software program designed for qualitative research, was used to organize the data.

Theoretical memos that served as a record of how codes were developed along with the properties of each category were written every time data was coded. Detailed memoing during the entire analysis process involved writing down ideas, assumed associations between categories, and theoretical reflections related to each of the emerging categories. Additionally, this process encouraged reflection and helped keep track of the coding process while allowing for critical questioning and necessary adjustments.

\section{RESULTS}

Participants' entries in their reflective diaries and responses to interviews provided information in response to Research Question 1, "What are Brazilian and Nigerian students' conceptions of learning?" Eleven of the 13 participants typed and two hand-wrote their diaries. Diary entries for all participants varied in length, format and depth. Most participants organized their daily entries according to the guiding questions. Approximately half the participants wrote lengthy daily reflections that were often a page long. The other half wrote shorter daily reflections consisting of about half a page. Data from the reflective diaries indicated participants wrote either about non-school or school related experiences, but most of the students ( 9 out of 13) wrote about non-school related learning experiences. Three out of thirteen $(23 \%)$ reported a more balanced split of non-school and school related learning experiences. Only one participant $(7.7 \%)$ described school related experiences more times than non-school related experiences. Nonschool related topics ranged from learning about culture through activities such as cooking, watching movies, music, artwork, sororities, and fraternities to learning experiences that taught participants values, such as being hopeful, polite, hardworking, and patient. Other non-school related learning experiences included playing an instrument, improving listening skills, parallel parking, twirling a flag, and using a gun safely. Participants also wrote about learning experiences that helped make their day-to-day life easier, such as how to use the different functions of an iPad, a fax machine 
and an automated teller machine (ATM). School related topics experiences included business capstone class assignments, petro physics, derivatives for calculus, and Rene Descartes' Theory on Realism. Participants addressed other issues about their learning experiences in their diaries, however participant responses were very varied and no clear themes emerged.

Interview transcripts revealed five different conceptions of learning identified by students from both countries. Conceptions of learning were described in terms of: 1) new/increase in knowledge, 2) acquisition of knowledge for practical application, 3) memorization, reproducing and studying, 4) understanding, and 5) a process not bound by context or time. Each theme is presented below with representative quotes and participants' nationality in parentheses.

Learning as increase in knowledge. Participants talked about learning in terms of acquiring new knowledge and/or increasing one's knowledge or being presented with new information and knowledge. This conception of learning is quantitative in nature, referring to the accumulation of knowledge. An example statement is:

I think I would say learning is picking up something I didn't know previously, basically and it depends, like in school, yeah I think that's just it, learning is finding out something I didn't know before or being exposed to something I didn't know, like getting more information. (Nigerian student)

Statements like this convey the belief that learning involves coming into contact with new information or skills. Learning was also described as an acquisition or increase in a particular skill:

Well when you learn your grow, you develop skills that you maybe you know don't even know that you have, it's difficult to explain, but like also, anything you didn't know before, like skills, different subjects, like culture too, not just learning in like a school. (Brazilian student)

When talking about gaining new knowledge in the learning process, participants noted knowledge and information are often transferred from teacher to student, and they often described teaching as the transference of knowledge. In addition to identifying teachers as one source for new knowledge, participants discussed personal experiences and the experiences of others as ways through which new information and knowledge is acquired. 
Learning as acquisition of knowledge for practical application. Participants discussed learning as acquisition of knowledge for practical application, often describing what purpose it serves. Participants generally did not discuss the purpose of learning within a school or educational context. Their responses focused more on real life applications. Representative statements are:

I'd say, being able to use something that you've actually been taught, in the sense that you can recall it later in the future not just what is being forced down into you, where you cram and you write an exam, pass and that's it, to me that's not learning, it's actually being able to use what you know, what you've been taught, that's learning.... Oh yes definitely, that's what I mean, learning should have a practical end, I don't want to learn something that I won't use in life and I should go further and say in my day to day life, to me then it's useless. We learn, or we should learn in order to be able to use it, so yes, it should be practical. (Nigerian student)

Central to this application-based conception of learning is practice and the importance of being able to practice what one learns. This focus was emphasized in comments regarding opportunities for hands-on experiences directly related to their education. Participants made statements such as:

Yeah, like so people can relate, not just classroom, but take it out the classroom, not just book, book and technical, but make the content and subject real, like give us something to do to make what we are learning real to us students...like an activity outside of class. Real life. (Brazilian student)

Such comments implied a shift from learning as passive with learners who receive new knowledge transferred either from the teacher or other sources to a more active process that involves practicing and utilizing the acquired knowledge.

Learning as memorization, reproducing and studying. This conception of learning was characterized by viewing learning as remembering and/or partly in terms of being able to reproduce something. For some participants learning was inseparable from memory:

I learn when I remember, to me, learning is like remembering when I get some new information and I can remember it later, and give it back, either in writing, like a test or paper, or I am able to tell someone else and I remember it all. (Nigerian student) 
Other statements implied that beyond remembering, the ability to explain something to someone else is perceived as an indication of learning:

To me I think, if I am able to remember something I have been told and taught, if I am remembering and explain to someone else, that how I know I've learnt something or if I am able to bring it up in a conversation, that's learning, I study too, when I study I learn too you know? (Brazilian student)

Learning as understanding. This conception of learning focused on understanding, with personal meaning being a prominent feature. Within this conception, developing and discovering meaning is important. Example comments include:

Hmmm, well I would say, understanding, making sense of it, in a way that makes sense to me, you know. You can't say you have learned something if you can't say you understand it and not just understand it exactly as it is taught to you, but in your own way. Make it your own. (Nigerian student)

Learning I think is when where you have the possibility to really understand something in our own view point, in our own. Ummm, learning for me is when we have possibility to comprehend, have comprehension about all the topics about one thing, when we have opportunity to solve doubts. (Brazilian student)

Learning as a process not bound by context or time. This conception of learning is characterized by the belief that learning occurs outside of schools and other formal educational settings. Participants expressed that they believe that learning takes place predominantly outside of school. Additionally they see life, from birth to death, and life's experiences as a learning process, stating that they believe all of life is a learning experience. They made statements such as:

We can learn outside of school...I think the school is $30 \%$ percent, $40 \%$ percent maybe, it can be different for each individual, but mainly I think, we learn mostly out of school. And I think in Brazil this is how I felt, that we learn a lot, more than in school, in life, outside of school....Like things that happen to you during day to day what you are doing...for me I say school $30 \%$ because I learn mostly from my family and people around me at home you know...they tell me things about life in general...sometimes I see things happen to them and I learn, like that. (Brazilian student) 
I think we may not always be aware of it, but we are learn in our day to day living, I think because mentally we know, we are told that school is where you come to learn, we expect to learn there, but are not always consciously expecting or consciously aware of learning outside of school, but I think we definitely do, I would dare say that I think for most people, or let me say for myself when I really sit to analyze and compare, I learn more outside of school than in school...I think you are learning until you die, everyone.(Nigerian student)

In response to Research Question 2, "Are there differences and/or similarities between their conceptions of learning and learning experiences in the United States?" themes emerged about conflict between their conceptions of learning and learning experiences in the U.S. For example, participants expressed the belief that students should work together and collaborate in learning environments. However, they reported experiencing competitive environments in the U.S.:

To me it should be cooperative, competitive makes everyone want to overshadow everybody and that way no one is learning anything, because for example, if there is someone who doesn't like competition, the person will actually lose out, but if everything is cooperative and you know, then students learn from each other, maybe a comment here, a comment there, that person will understand what is being taught better, competition, I feel, can destroy morale, because I believe learning is encouraged when people do it together, at any level, in any setting you know, not just the classroom, when there are other people around you learning, you open up and learn more.....I feel. (Nigerian student)

No we are not encouraged to compete, errr, I think it's a social, cultural thing, I first heard about it, then saw it for myself, about the selfishness of American people, the individual thing, maybe it's not a bad thing, but American students are like "I will do the best for myself, and you do the best for yourself" and errr, I find that back at home you can talk to more people and bond, with other classmates and here there is more of the competition feeling, with people used to doing it by themselves, yeah competition is not so big in Brazil. (Brazilian student)

Statements such as this convey the discrepancy between participants beliefs about competition versus collaboration in the learning process and their experiences in the United States. Participants basically expressed the belief that students should work together and collaborate in 
learning environments. However, their experiences in the United States involve competitive environments. Their views on collaboration are directly in contrast with their views on competition and convey what they believe to be the cons of competition and pros of collaboration.

Participants also reported that they experienced a great deal of hands-on learning in their home countries and it is central to their conception of learning. However, they experienced a lack of hands-on learning in the U.S.:

I think that here in the United States, it's really based on the book and if you wanna do good you have to do your research, and then I feel like back home the professors, they are more clear, like I'll go back to the instructions, they give you more, you'll be able to see more things than you see here, for example in one of my classes in Brazil, we had to learn, it was very similar to my capstone class, somehow. The difference was we actually went to a factory where we saw the raw material from Argentina and then you are actually able to see the whole process of the raw material becoming flour and then we had access to the books, so then that's how we made our report. (Brazilian student)

So it's a little difficult. In Nigeria, we didn't have so much to do like here, some we did in classes, but a lot of it was take it outside the classroom and do it in life, you know, like you are learning, take it home and then see how you can connect or ummm link it to life and make sense of it that way, so everything was not classroom, classroom, like here, it was more than classroom, like it was life you know. (Nigerian student)

These statements indicate a stark difference between their home countries of Nigeria and Brazil and the United States in terms of hands-on learning. Diversity is the one area where students' experience a similarity between their learning experiences at home and in the U.S. An example comment is:

I think, like not really similar, I think like in a way because, you know Nigeria is a different culture, so you know, it's like different, it's like almost all African there, here and in America it's like different people, so at the end of the day if I meet someone from a different tribe in Nigeria, I can learn something new from them, same thing here, if I meet someone from a different country, I feel like that's a similarity like you tend to learn from people outside, outside, your own you know, own, tribe country or whatnot, so I think that's kinda like a similarity, yeah. (Nigerian student) 
I'd say, because where I grew up, it's a big city, so it was very diverse, lots of different people, from different tribes, countries, so but here, in Atlanta, in GSU, it's also diverse, a lot more diverse I would say, and so though its broader in a sense, I would say it's a similarity a lot of cultures from all over in the world, so in both places, you are exposed, maybe to different degrees, to different viewpoints, experiences, perspectives, and that is very vital to learning you know...that exposure. (Brazilian student)

Embedded in these views on diversity are beliefs about the benefits it provides such as being exposed to and learning about and from different cultures and people from different backgrounds.

In response to Research Question 3, "Are there differences and/or similarities between the two groups in their conceptions of learning?" no clear themes emerged regarding differences in Brazilian and Nigerian students' conceptions of learning despite direct comparisons of the two countries. Participants expressed that the process of adapting to learning in the U.S. as difficult:

Very hard, like if I should put it on a scale of zero to ten, I would put ten and I am thinking of this when I first started going to college here, because I am a transfer student because the systems work a little different because, here, you have, every time you ask someone something, they address you to the website, oh go to the website go to desire2learn, go to your paws account, you do not have someone, you don't have a mentor that says, I'm gonna talk to you, like look, that's how it was when I got started, go here, go there, and I know from my culture, Brazilian people we are very passionate about helping people, we are not afraid to help others, with learning too, we help each other, together and our way of helping people, like I do it, we are very hands-on. And then the American culture is very private, individualist, and there is a conflict for those students coming here, and I can't imagine, for those also doing the ESL, how hard it is for them because they also have to learn the language and be with a big group of teachers, it is such a diverse school, such a diverse body of teachers, where sometimes you can be in a classroom with a teacher who also has an accent, so it must be really hard for them. (Brazilian student)

Other statements addressed more specific things that were new and required adjustment, such as the relationship between old and young people. Some example statements were: 
So I think that was one of the things I found challenging and when I first came to this country and ummm...the way people view things, people see things quite differently from how I as Nigerian sees things and I think it's a cultural thing. Ummm this is quite basic anyways, like when you are talking to someone who is older than you are, you know, there's a couple of terms you can't us, how you refer to them, how you address them, like here people talk to older people as if they are their age mates, call them by the first names and things like that, you know, just those basic things and it all piled up and I wasn't used to things like that, so I had to slowly adjust, so in relation to that, in the classroom, I would see students talking to the teacher any way they want, and that was new to me, students arguing with teachers, telling them they were wrong, even when the teachers were a lot older than us. I wasn't used to that, you give them that respect because they are older and because they are our teachers you no...so I have had to adjust. (Nigerian student)

\section{DISCUSSION AND CONCLUSIONS}

Data from the reflective diaries indicated students' awareness of how much learning takes place outside formal school environments. A majority of students described non-school related learning experiences more often than they did school related experiences. Previous research with Brazilian and Nigerian students in their countries of origin also indicates beliefs that learning is not reserved for formal learning environments but is embedded in everyday life (Crabtree \& Sapp, 2004; Iyamu \& Ukadike, 2007). This finding and its alignment with previous research is interesting because it indicates that, whether Brazilian and Nigerian students are home or abroad they consider learning as a process not limited to the classroom. Educators that work with this population may wish to encourage students to pay attention to the learning experiences they have beyond the classroom. Specifically, drawing students' attention to how they learn outside of school could inform what methods and strategies they chose to use in the classroom. Conceptions of learning revealed in this study may importantly be viewed in terms of active and passive learning. The theme of acquiring knowledge for practice indicates ideas about learning as an active process. Research has established that in order for students to develop mastery in any concept or skill, they must go beyond knowledge acquisition and learn how to apply and practice it. This process is vital to students' academic achievement because it speeds up learning, helps with long-term retention, and facilitates recall (Seels \& Glasgow, 1997).

Previous research with Nigerians in their country of origin reported a preference for practical instead of theoretical learning (Watkins \& Akande, 1994). An important finding of this study is that Nigerian students 
whether home or abroad view learning as a practical endeavor involving practice, indicating an active approach to learning. The theme of learning as understanding is another conception involving action, where gaining, developing, and discovering personal meaning from knowledge is important. The view that learning is not bound by context or time may also be considered active. Students discussed that they learn in a variety of environments and will continue to learn over their life span. Research on active learners has established that they utilize higher order thinking and problem solving skills and are more enthusiastic about learning which leads to greater academic success (Anderson et al., 2005; Emelo, 2013; Petress, 2008; Thaman, Dhillon, Saggar, Gupta, \& Kaur, 2013; Wolfe, 2006).

The view that learning is the accumulation of knowledge may be considered passive since students often describe themselves as the recipients of information from teachers. Another example of passive learning is the view of learning as memorization since students discussed this category in terms of being able to remember and reproduce information rather than do something with the information. Research on passive learners established that they have diminished motivation and enthusiasm, are less likely to ask questions, apply what they learn, and engage the information they receive, an approach to learning that often presents a challenge to academic achievement (Anderson et al., 2005; Emelo, 2013; Petress, 2008; Thaman et al., 2013; Wolfe, 2006). It is interesting to note that both active and passive conceptions of learning emerged from Brazilian and Nigerian students. It is also important to note specifically that elements of both active and passive conceptions of learning were present in individual participant responses. Perhaps this finding is a result of students transitioning from cultures that focus on passive learning to one that focuses on active learning. In any case, educators working with this population may wish to foster and encourage active learning.

It is interesting to compare participants' conceptions of learning to previous research on U.S. students' conceptions of learning. Two conceptions of learning (learning as gaining information and learning as a process not bound by time or place) that emerged in this study were also reported in earlier research with American students (Hong \& Salili, 2000; Purdie \& Hattie, 2002). It is important to consider that conceptions of learning may be shifting as participants adapt to the culture in the United States. International students studying in other cultures may have "hybrid" conceptions of learning, or ideas that are influenced both by their culture of origin and the culture they are experiencing while studying abroad. The fact that participants in this study report conceptions of learning similar to American students may indicate their conceptions of learning are shifting as they experience American culture. Thus the findings that this study captured may be reflective of the intersection of two cultural influences, indicating that students still hold on their conceptions of learning from their 
cultures of origin but are influenced by the conceptions of learning they encounter in American culture.

Findings on differences between learning conceptions and experiences are not surprising when considering previous research on classroom environments in the U.S. American classrooms are predominantly learner centered where students think critically about content, express perspectives in class, participate in dialogue, and demonstrate understanding (Smithee, Greenblatt, \& Eland, 2013). Additionally, research has found that classrooms in the U.S. are environments where there are expectations of independent work, which can hinder collaboration. The differences reported between conceptions and experiences may be contributing to participants' reports that adapting to learning in the United States is difficult. It is interesting to view these reported difficulties in light of international students' challenges reported by previous research which include the individualist nature of the U.S. culture, increase in workload, being away from family and friends, new environments, and an increase in technology use (Abe, Talbot, \& Geelhoed, 1998; Brown, 2008; Liu, 2011; Okorocha, 2010; Sam, 2001; Trice, 2005). It is possible that one explanation for why international students report these specific set of challenges is the discrepancy that exists between their conceptions and experiences once they are in the United States. Institutions may wish to directly address the conflict between conceptions of learning and experiences in addition to these identified issues through providing international students with workshops and courses.

The one theme that reflected a similarity between learning beliefs and experiences in the U.S. was diversity. Participants expressed the belief that diversity is important because it presents opportunities to learn from different people and allows exposure to different viewpoints, experiences, and perspectives, which is very vital to learning. This belief in the value of diversity is supported by the diverse learning environments they experience in the U.S. Research outlined several benefits of diversity in higher education, including enriching educational experiences, promoting personal growth by challenging stereotypes, encouraging critical thinking, learning to communicate effectively with people of varied backgrounds, and fostering mutual respect and teamwork (Hardy \& Tolhurst, 2014; Tienda, 2013; Turner, 2013). It is important to note that participants in this study were attending an urban, diverse institution where their belief in the importance of diversity in a learning environment was likely matched by their experiences. This value for diversity underlines need for educators working with Brazilian and Nigerian students to create opportunities for students to interact and work with various groups of students and facilitate a context for diverse points of view to be expressed in the classroom. Programs and institutions that are explicit about diversity as a core value 
would be contributing toward international students feeling more comfortable in their educational environment.

No clear themes emerged regarding differences in Brazilian and Nigerian international students' conceptions of learning. Thus results indicate noticeably similar conceptions of learning among students from both countries. Hofstede's Theory of Cultural Dimensions (1986) may provide one explanation for this finding since most West African and South American nations fall along similar sides on the five cultural dimensions. Through his early seminal work on national work culture in 72 countries Hofstede (1986) identified five cultural dimensions: individualismcollectivism, power distance, uncertainty avoidance, masculinityfemininity, and long-versus short-term orientation (Jaju, Kwak, \& Zinkhan, 2002). Individualism-collectivism describes how individuals define themselves within society and measures the extent of the role of the individual versus the role of the group in a society. The dimension of power distance represents the extent to which members of a society expect and accept power distribution within the society. Uncertainty avoidance measures the degree to which members of a society feel threatened by uncertain, ambiguous, and unstructured situations. The dimension of masculinity-femininity represents the polarization between gender roles in any given society. Masculine cultures are male dominated societies characterized by clearly distinct gender roles, while feminine cultures in contrast have overlapping gender roles. Long-term orientation cultures foster virtues oriented towards future rewards, such as adaptation, perseverance, and thrift, while short-term orientation cultures foster virtues oriented toward past and present, such as respect for tradition, preservation of face, and fulfilling social obligations. Brazil and Nigeria are identified as cultures that are highly collectivistic and masculine with high power distance, weak uncertainty avoidance, and short-term orientation (Hofstede, 1986). Beliefs about learning in collectivistic cultures are centered on the collaborative process, and there is a general preference for group learning (Al-Fraih, Duffy, Monserrat, \& Baker, 2012; Foley \& Mitsis, 2004; Hofstede, 1986; Jaju, Kwak, Zinkhan, 2002; Signorini, Wiesemes, \& Murphy, 2009). Students from high power distance cultures expect to learn and abide by the truth provided by teachers, and thus learning mostly involves teachers transmitting content to students. Cultures with weak uncertainty avoidance have learning environments characterized by flexibility with teachers as guides and facilitators in the learning process (Al-Fraih et al., 2012; Foley \& Mitsis, 2004; Jaju et al., 2002; Signorini et al., 2009). However, the similarities between the Brazilian and Nigerian cultures on Hofstede's dimensions and conceptions of learning among students from both countries should not be interpreted as an indication that these two groups of international students are homogenous and share identical learning experiences. Rather, implications for educational 
practice drawn from the findings for these two groups should serve as important frameworks to guide educators and institutions.

\section{IMPLICATIONS AND SIGNIFICANCE}

Information on international students' conceptions of learning is significant for a number of reasons. Research has argued that there is very little congruence between university students' conceptions of learning and those of their teachers, citing this discrepancy as one of the reasons for learning difficulties in higher education (Perry, 1970; Burnett, Pillay, \& Dart, 2003). Hofstede (1986) emphasized that teachers at all levels of education need to be trained to become intellectually and emotionally accustomed to the fact that in other societies people learn differently, especially as learning environments become more culturally diverse in order to be able to effectively develop culturally inclusive teaching approaches. Learning shapes the main ideas of educational practice. The way individuals define learning and beliefs about the way learning occurs has important implications for educators who facilitate learning. An understanding of learning theories and conceptions provides instructional designers with verified instructional strategies and techniques for facilitating learning as well as a foundation for intelligent strategy selection (Ertmer \& Newby, 2013). It is a fundamental belief that when educators gain a full understanding of students' conceptions of learning, they can design better teaching and curricula or instructional environments (Burnett, Pillay \& Dart, 2003; Chin \& Brown, 2000; Tsai, 2009). A significant finding of this study is that Nigerian and Brazilian participants have multiple conceptions of learning. According to Lee (1998), students with multiple conceptions of learning pay attention to learning conditions and subject difficulty level. Furthermore, Lin and Tsai (2008) believe that students with multiple conceptions of learning use higher levels of cognitive and metacognitive strategies and thinking skills, such as self-monitoring, and a selection of different problem-solving strategies that are effective in their academic achievement. In other words, students who have multiple conceptions of learning use a combination of various learning methods to achieve academic success. Even though the focus of this study did not extend to learning strategies, it can be inferred that the population employs a variety of learning methods. Educators who work with students from Brazil and Nigeria may consider encouraging them to explore and think about the different ways in which they conceptualize learning and expose them to the different conceptions of learning identified in the literature. Additionally, educators and teachers can help students understand how learning conceptions influence and shape learning strategies and methods.

This study is also significant because it addresses the importance of understanding definitions of learning. Saljo (1976) early on emphasized, 
"Learning does not exist as a general phenomenon. To learn is to act within man-made institutions and to adapt to the particular definitions of learning that are valid in the educational environment in which one finds oneself" (p.106). Different educational environments define learning according to "different socially and culturally established conventions with respect to what counts as learning" (p.104). In this regard, international students come to institutions of higher education in the U.S. with a variety of culturally and socially influenced definitions of learning and must learn how to function and integrate into already established learning environments with existing definitions of learning. For this joining of different definitions of learning to work effectively, it is important that all parties involved have an understanding of each other's definition of learning. This study provides educators in universities in the U.S. with information on how students from Brazil and Nigeria define learning. On a broader level, this research is significant because it expands on the relatively small literature on international undergraduate students from Brazil and Nigeria studying in the U.S. This study sheds light on a segment of the international undergraduate student population not previously addressed in the literature (Dahlin \& Regmi, 1997; Marshall et al., 1999; Purdie et al., 1996; Tsai, 2009). The general trend in conceptions of learning research is to rely on an East-West dichotomy as the basis for cross-cultural theorizing, and this study offers additional lens with which to view learning by a much-understudied population. This study reports findings that provide needed information on Brazilian and Nigerian international students, populations that are increasingly becoming part of classrooms in universities across the U.S.

One limitation of this study is the reliance on self-report data. Future studies could combine additional techniques such as observations together with self-report to gain a deeper understanding of conceptions of learning. Another limitation of this study is maturational effects are not examined. Future research could examine students' conceptions of learning at the beginning, middle, and end of their study abroad experience to determine if length of stay in the U.S. may change learning conceptions over time. Importantly, future research could also examine the relationship between Brazilian and Nigerian students' conceptions of learning and academic achievement, as has been done with other populations. There is the need for a bridge between research on the learning experiences of international students and educational practice. Through reflective diaries and interviews themes emerge that paint a clear picture of the learning conceptions and experiences of Brazilian and Nigerian international students. Findings inform instructional, curriculum, and program designers and educators who work directly and indirectly with this population and provide valuable information for making decisions regarding learning objectives and strategies. Understanding how students learn is useful in 
determining what kinds of programs can be created to help international undergraduate students succeed academically and overall transition smoothly into the U.S. education system.

\section{REFERENCES}

Abe, J., Talbot, D. M., \& Geelhoed, R. J. (1998). Effects of a peer program on international student adjustment. Journal of College Student Development, 39(6), 539-547.

Abhayawansa, S., \& Fonseca, L. (2010). Conceptions of learning and approaches to learning: A phenomenographic study of a group of overseas accounting students from Sri Lanka. Accounting Education: An International Journal, 19 (5). 527-550. doi: 0.1080/09639284.2010.502651

Adelegan, F. O., \& Parks, D. J. (1985). Problems of transition for African students in an American university. Journal of College Student Personnel, 26 (6), 504-508.

Al-Fraih, H. S., Duffy, J., Monserrat, S. I., \& Baker, G. (2012). Cross cultural comparison of college student preferences and ranking of instructor attitudes. International Journal of Business and Public Administration, 9(1).

Allan, B. (2003). Approaches to learning and academic achievement of Filipino students. The Journal of Genetic Psychology, 164, 101-114. doi: 10.1080/00221320309597506

Anderson, R. E., Dixon, A. L., Jones, E., Johnston, M. W., LaForge, R. W., Marshall, G. W., \& Tanner, J. F. (2005). The scholarship of teaching in sales education. Marketing Education Review, 15 (2), 1-10. doi: 10.1080/10528008.2005.11488899

Beoku-Betts, J. (2004). African women pursuing graduate studies in the sciences: Racism, gender bias, and third world marginality. NWSA Journal 16(1), 116-135. doi:10.1353/nwsa.2004.0026

Boulton-Lewis, G., Marton, F., Lewis, D., \& Wilss, L. (2000). Learning in formal and informal contexts: conceptions and strategies of Aboriginal and Torres Strait Islander University students. Learning and Instruction, 10 (5), 393-414. doi:10.1016/S0959-4752(00)00005-0

Brown, L. (2008). The incidence of study-related stress in international students in the initial stage of the international sojourn. Journal of Studies in International Education, 12 (1), 5-28. doi: 10.1177/1028315306291587

Burnett, P. C., Pillay, H., \& Dart, B. C. (2003). The influences of conceptions of learning and learner self-conception high school students' approaches to learning. School Psychology International, 24, (1), 54-66. doi: 10.1177/0143034303024001621

Cano, F., \& Cardelle-Elawar, M. (2004). An integrated analysis of secondary school students' conceptions and beliefs about learning. European Journal of Psychology of Education,19, (2), 167-187. doi: 10.1007/BF03173230

Castaneda, R. H. (2008). The graduate experience: living and studying abroad (a case study). RELIEVE, 10 (2), 2-16.

Charmaz, K. (2006). Constructing grounded theory. A practical guide through qualitative analysis. Thousands Oaks: Sage.

Chin, C., \& Brown, D. E. (2000). Learning in science. A comparison of deep and surface approaches. Journal of Research in Science Teaching, 37 (2), 109-138

Constantine, M. G., Anderson, G. M., Berkel, L.A., Caldwell, L. D., \& Utsey, S. O. (2005). Examining the cultural adjustment experiences of African international college students: A qualitative analysis. Journal of Counseling Psychology, 52 (1), 57-66. doi: 10.1037/0022-0167.52.1.57

Crabtree, R. D., \& Sapp, D. A. (2004). Your culture, my classroom, whose pedagogy? Negotiating effective teaching and learning in Brazil. Journal of Studies in 
International Education, 8(1), 105-132. doi: 10.1177/1028315303260826

Dahlin, B., \& Regmi, M. P. (1997). Conceptions of learning among Nepalese Students. Higher Education, 33(4), 471-493. doi: 10.1023/A:1002992411868

Downie, A. (2005). Latin American Countries Push More Students to Study Abroad. Retrieved from the Chronicle of Higher Education Website. http://chronicle.com/article/Latin-American-Countries-Push/128584/

Emelo, R. (2013). Engage passive learners. Chief Learning Officer, 12 (1), 30-33.Ertmer, P.A., \& Newby, T.J. (2013). Behaviorism, cognitivism, constructivism: Comparing critical features from an instructional design perspective. Performance Improvement Quarterly, 26 (2). 50-72. doi: 10.1111/j.1937-8327.1993.tb00605.x

Fidalgo-Neto, A. A., Tornaghi, A. J., Meirelles, R. M., Berçot, F. F., Xavier, L.L., Castro, M. F., \& Alves, L. A. (2009). The use of computers in Brazilian primary and secondary schools. Computers \& Education, 53 (3), 677-685. doi: 10.1016/j.compedu.2009.04.005

Foley, P., \& Mitsis, A. (2004). The effects of students' cultural values on their studentdriven learning experience. Working Paper Series. Victoria University, Melbourne, Australia.

Glaser, B. G., \& Strauss, A. L. (1967). The discovery of grounded theory: Strategies for qualitative research. New York: Aldine de Gruyter.

Guillemin, M., \& Gillam, L. (2004). Ethics, reflexivity, and 'ethically important moments in research. Qualitative Inquiry, 10(2), 261-280. doi: 10.1177/1077800403262360

Hallberg, L. M. (2006). The "core category" of grounded theory: Making constant comparisons. International Journal of Qualitative Studies on Health and Wellbeing 1,(3), 141-148. doi: 10.1080/17482620600858399

Hall, W. A., \& Callery, P. (2001). Enhancing the rigor of grounded theory: incorporating reflexivity and relationality. Qualitative Health Research, 11(2), 257-272. doi: $10.1177 / 104973201129119082$

Hardy, C., \& Tolhurst, D. (2014). Epistemological beliefs and cultural diversity matters in management education and learning: A critical review and future directions. Learning \& Education. 13(2), 265-289. doi: 10.5465/amle.2012.0063

Hofstede, G. (1986). Cultural differences in teaching and learning. International Journal of Intercultural Relations, 10(3), 301-320. doi:10.1016/0147-1767(86)90015-5

Hong, Y. Y., \& Salili, F. (2000). Challenges ahead for research on Chinese students' learning motivation in the new millennium. Journal of Psychology in Chinese Societies, 1(2), 1-12.

Horsburgh, D. (2003). Evaluation of qualitative research. Journal of Clinical Nursing, 12(2), 307- 312. doi: 10.1046/j.1365-2702.2003.00683.x

International Institute of Education. (2015). Open Doors Report. Retrieved from http://www.iie.org/Research-and-Publications/Open-Doors

Iyamu, E. O., \& Ukadike, J. O. (2007). Perception of self-directed cooperative learning among undergraduate students in selected Nigerian universities. International Journal of Information and Communication Technology Education, 3(4), 13-20. doi: $10.4018 /$ jicte. 2007100102

Jaju, A., Kwak, H., \& Zinkhan, G. M. (2002). Learning styles of undergraduate business students: A cross-cultural comparison between the US, India and Korea.

Marketing Education Review, 12(2), 49- 60.doi10.1080/10528008.2002.11488787

Johnson, R., \& Waterfield, J. (2004). Making words count: the value of qualitative research. Physiotherapy Research International, 9 (3), 121-131. doi: 10.1002/pri.312

Jones, M. E. (2008). International students' cross-cultural experiences of learning. International Journal of Asian Pacific Studies, 4 (2), 39-71.

Lee, Y. (1998). Assessing and fostering senior secondary school students' conceptions and understanding of learning through authentic assessment. Master's Thesis, Hong Kong: University of Hong Kong.

Lietz, C. A., Langer, C., \& Furman, R. (2006). Establishing trustworthiness in social work 
research: Implications from a study regarding spirituality. Qualitative Social Work, 5(4), 441-458. doi: 10.1177/1473325006070288

Lin, M., \& Tsai, C. (2008). Conceptions of learning management among undergraduate students in Taiwan. Management Learning, 39, 561-578. doi: $10.1177 / 1350507608096041$

Liu, L. (2011). An international graduate student's ESL learning experience beyond the classroom. TESL Canada Journal, 29(1), 77-92. doi: 10.18806/tesl.v29il.1090

Macbeth, D. (2001). On reflexivity in qualitative research: two readings, and a third. Qualitative Inquiry 7 (1), 35-68. doi: 10.1177/107780040100700103

Marshall, D., Summers, M., \& Woolnough, B. (1999). Students' conceptions of learning in an Engineering context. Higher Education, 38 (3), 291-309. doi: 10.1023/A:1003866607873

Marton, F. (1981). Phenomenography: Describing conceptions of the world around us. Instructional Science, 10 (2),177-200. doi: 0.1007/BF00132516

McLean, M. (2001). Can we relate conceptions of learning to student academic achievement? Teaching in Higher Education, 6, 399-413. doi: 10.1080/13562510120061241

McGuinness, M., \& Simm, D. (2005). Going global: long-haul fieldwork on undergraduate Geography. Journal of Geography in Higher Education, 29(2), 241-253. doi: $10.1080 / 03098260500130478$

Okorocha, E. (2010). International Students' Experience in UK Higher Education. United Kingdom: Abaramis Academic Publishing.

Perry, W. G. (1970). Forms of intellectual and ethical development in the college years: A scheme. New York: Holt, Rinehart and Winston.

Petress, K. (2008). What is meant by "active learning"? Education, 128 (4), 566-569.

Phinney, J. S., \& Onwughalu, M. (1996). Racial identity and perception of American ideals among African American and African students in the United States. International Journal of Intercultural Relations, 20 (2), 127-140. doi: 10.1016/01471767(95)00040-2

Prinsloo, P., Slade' S., \& Galpin. F. (2011). A phenomenographic analysis of students' reflections in online learning diaries. Open Learning: The Journal of Open, Distance and e-learning, 26(1), 27-38. doi: 10.1080/02680513.2011.538562

Purdie, N., Hattie, J., \& Douglas, G. (1996). Student conceptions of learning and their use of self-regulated learning strategies: A cross-cultural comparison. Journal of Educational Psychology, 88 (1), 87-100. doi: 10.1037/0022-0663.88.1.87

Purdie, N., \& Hattie, J. (2002). Assessing students' conceptions of learning. Australian Journal of Educational and Developmental Psychology, 2, 17-32.

Reynolds, A. L., \& Constantine, M. G. (2007). Cultural adjustment difficulties and career development of international students. Journal of Career Assessment, 15 (3), 338350.doi: 10.1177/1069072707301218

Saljo, R. (1976). The educational construction of learning. In J. Richardson, M. Eysenck, \& D. Piper (Eds.), Student learning: Research in Education and Cognitive Psychology (pp. 101-108). Philadelphia: The Society for Research into Higher Education. Open University Press.

Sam, D. L. (2001). Satisfaction with life among international students: An exploratory study. Social indicators research, 53(3), 315-337. doi: 10.1023/A:1007108614571

Santilli, V., Miller, A. N., \& Katt, J. (2011). A comparison of the relationship between instructor nonverbal immediacy and teacher credibility in Brazilian and U.S. classrooms. Communication Research Reports 28(3), 266-274.

Seels, B., \& Glasgow, Z. (1997). Making Instructional Design Decisions. Columbus, OH: Prentice Merrill.

Shenton, A. K. (2004). Strategies for ensuring trustworthiness in qualitative research projects. Education for Information 22 (2), 63-75.

Signorini, P., Wiesemes, R., \& Murphy, R. (2009). Developing alternative frameworks for 
exploring intercultural learning: a critique of Hofstede's cultural difference model. Tracking in Higher Education, 14(3), 253-264. doi: 10.1080/13562510902898825

Smithee, M., Greenblatt, S. L., \& Eland, A. (2013). U.S. culture series: U.S. classroom culture. Washington, DC: NAFSA

Strauss, A. L., \& Corbin, J. M. (1998). Basics of Qualitative Research: Grounded theory procedures and techniques ( $2^{\text {nd }}$ ed.). Newbury Park, CA: SAGE.

Sunal, C. S., Inuwa, R., Sunal, D. W., \& Haas, M. E. (2001). Three Nigerian primary school teachers: classroom days. Journal of Research in Childhood Education, 16(1), 94108.doi: 10.1080/02568540109594977

Tienda, M. (2013). Diversity $\neq$ Inclusion: Promoting integration in higher education. Educational Researcher 42 (9), 467 - 475. doi: 0013189X13516164

Thaman, R. G., Dhillon, S. K., Saggar, S., Gupta, M. P., \& Kaur, H. (2013). Promoting active learning in respiratory physiology - positive student perception and improved outcomes. National Journal of Physiology, Pharmacy and Pharmacology. 3(1), 27-34. doi: 10.5455/njppp.2013.3.27000

Travers, C. (2011). Unveiling a reflective diary methodology for 91exploring the live experiences of stress and coping. Journal of Vocational Behavior, 79 (1), 204-216. doi: $10.1016 /$ j.vb.2010. 11.007

Trice, A. G. (2005). Navigating in a multinational learning community: Academic departments' responses to graduate international students. Journal of Studies in International Education, 9 (1), 62-89. doi: 10.1177/1028315304271664

Tsai, C., \& Kuo, P. (2008). Cram school students' conceptions of learning and learning science in Taiwan. International Journal of Science Education, 30(3). 353-375. doi: 10.1080/09500690701191425

Tsai, C. (2009). Conceptions of learning science among high school students in Taiwan: a phenomenographic analysis. International Journal of Science Education, 26 (4).

Turner, C. S. (2013). Advancing diversity in higher education. Journal of Diversity in Higher Education, 6 (3) 155-157.

Vermunt, J. D., \& Vermetten, Y. J. (2004). Patterns in student learning: Relationships between learning strategies, conceptions of learning, and learning orientations. Educational Psychology Review, 16(4), 359-384.

Watkins, D., \& Akande, A. (1994). Approaches to learning of Nigerian secondary school children: Emic and etic perspectives. International Journal of Psychology, 29(2), $165-182$.

Wilton, L., \& Constantine, M.G. (2003). Length of residence, cultural adjustment, difficulties and psychological distress symptoms in Asian and Latin American international college students. Journal of College Counseling, 6, 177-186.

Wolfe, K. (2006). Active Learning. Journal of Teaching in Travel and Tourism. 6(1), 77-82.

CAROL ASHONG, PhD, is an instructor of education. Her research focuses on culture and learning, international, immigrant and refugee student populations. She recently taught educational psychology courses at Georgia State University.

E-mail: Carol.ashong@gmail.com

NANNETTE COMMANDER, Ph.D. is a Professor in the Department of Educational Psychology and Special Education at Georgia State University.

E-mail: Ncommander@gsu.edu

Manuscript submitted: September 9, 2015

Manuscript Revised: January 17, 2016

Accepted for publication: February 20, 2016 